\title{
Perceptual entitlement and basic beliefs
}

\author{
Peter J. Graham
}

Published online: 2 September 2010

(C) The Author(s) 2010. This article is published with open access at Springerlink.com

\section{In Perception and Basic Beliefs: Zombies, Modules, and the Problem of the} External World (Oxford University Press, 2009), Jack Lyons provides a psychological criterion of basicality to defend a broadly reliabilist account of perceptual warrant, while simultaneously raising a host of difficulties for evidentialism. I will focus on and criticize his response to the clairvoyant powers case. I will then offer him another solution to the clairvoyant powers case, which applies equally well to the brain-in-a-vat. Two birds with one stone, you might say. ${ }^{1}$

2. What's all the fuss about basic beliefs? Mental state foundationalists (MSF) thought beliefs formed through "acquaintance" or "immediate apprehension" about our own conscious sensations and conscious perceptual representations were basic.

\footnotetext{
${ }^{1}$ My use of 'warrant' broadly follows Burge's (2003). Warrants are epistemic rights to believe. They are positive epistemic statuses-statuses understood in terms of promoting truth and avoiding error-that attach primarily to beliefs. Warrant does not entail truth; warranted false belief is possible. Warrant is not that property which converts true belief into knowledge. There is more than one kind of warrant, or more than one kind of contribution to warrant. Reasons are warranted propositional attitudes, paradigmatically warranted beliefs. Reasons connect to reasoning. When reasons warrant, the individual possesses an argument for warranted belief. Entitlements are warrants or contributions to warrant that are not reasons. The field tends to use 'justification' and 'justified' generically for warrant. The field in turns tends to rely heavily on intuitive reactions to cases to determine the extension of 'justification' and 'justified.' I agree with Stewart Cohen and William Alston that this practice deserves scrutiny. One reason involves that fact that in ordinary English these terms connect to the activity of justifying one's belief to another, to the activity of citing or giving a justification or argument in favor of a belief. This activity is restricted to language users with the capacity to critically reason. But many epistemologists intend their use of the words to be much broader, and to cover the epistemology of beliefs not supported by exercises of critical reason. Another reason involves the plurality of epistemic statuses epistemologists have uncovered in the last forty years. Calling them all 'justification' is apt to lead nowhere, and only distract from further investigation into the natures of various epistemic statuses and their relations. Lyons follows common practice. He relies on intuitions about whether a belief is "justified" or not. I shall take him to be talking about warrant. I mostly agree with his intuitions about cases.
}

P. J. Graham (ه)

University of California, 900 University Avenue, Riverside, CA, USA

e-mail: peterg@ucr.edu 
Perceptual beliefs about external, physical objects then inferentially derived their warrant from basic beliefs about one's own mind.

Mental state foundationalism (MSF) has fallen out of favor. Why should warrant for belief about external, physical bodies, events, and relations require inference from introspective beliefs? Animals and small children can't refer to their sensations or perceptions. Even adults aren't very good at it. Should only trained introspectionists enjoy perceptual warrant? And if history is our guide, no such inference seems forthcoming. External world skepticism follows.

In its aftermath, three schools emerged: coherentism, and two versions of external object foundationalism (EOF).

Coherentists denied basic beliefs altogether; warrant resides exclusively in "coherence" relations among beliefs. Scientific theorizing proved the model.

Coherentism also gets perceptual warrant all wrong. Coherentism ignores the bedrock role perception plays. The isolation objection shows why (Lyons 2009, pp. 30-34). Though coherence relations are surely relevant to warrant, perception itself is fundamental to empirical warrant.

Most epistemologists now endorse some version of EOF. Like MSF, and unlike coherentism, EOF asserts the existence of basic beliefs. Unlike MSF, perceptual beliefs-beliefs non-inferentially formed through perception about external, physical objects, events, and relations-are themselves paradigmatically basic.

Broadly speaking, there are two varieties of EOF: internalist and externalist. Evidentialism is the most familiar version of the "internalist" variety. Like MSF, evidentialism sees conscious sensations and conscious perceptual representations as fundamental to empirical warrant. Perceptual beliefs are warranted "directly" by the conscious sensations or perceptual representations that occasion them. "Experiences" are seen as non-doxastic states that "evidentially justify" the beliefs they cause and sustain.

Reliabilism is the popular "externalist" version. Reliabilists think warrant consists in reliability. Perceptual belief enjoys prima facie warrant if and only if perception produces mostly true beliefs.

In his landmark 1979 paper "What is Justified Belief?" Alvin Goldman provided the following "master argument" for reliabilism. First, perception, introspection, good reasoning, and memory all intuitively confer, extend, and preserve "justifiedness." Wishful thinking, hasty generalization, and emotional attachment intuitively do not. Second, perception and so on are unconditionally or conditionally reliable. Wishful thinking, hasty generalization, and so on, are not. So the intuitively warrant conferring processes are reliable, and the processes the intuitively fail to confer warrant are unreliable. Goldman concluded that the best explanation of this co-variation was that "justifiedness" strongly supervenes on the matter of fact reliability of the belief-forming process.

Evidentialists accept Goldman's premises; they reject his inference. Laurence BonJour (1980) and Keith Lehrer (1990) argued that the sheer reliability of a beliefforming process fails to confer warrant on the beliefs it typically causes and sustains. Norman acquires a reliable "clairvoyant" process by fluke or mutation that he knows nothing about. Though reliable, his beliefs formed by the process lack warrant. Lehrer et al. (1983) argued reliability couldn't be necessary either. The 
massively deceived, disembodied brain-in-a-vat enjoys warranted empirical beliefs, never mind the lapse in matter of fact reliability. Goldman's strong modal conclusion doesn't follow from his largely uncontroversial premises.

Evidentialists think both cases reveal what's essential to empirical warrant: the presence of conscious, sensory impressions or conscious, perceptual representations. Absent in the clairvoyant powers case, the reliably formed beliefs lack warrant. Present in the brain-in-a-vat case, the unreliably formed beliefs nevertheless enjoy warrant. "Justifiers" are "internal" conscious mental states and events, not "external" reliable processes. Though coherentists came up with the counterexamples, evidentialists happily deploy them.

3. Jack Lyons enters the debate at this stage in the fray. Lyons diagnoses the clairvoyant powers type cases as relying on insufficient attention to "basicality." In clairvoyance cases, Lyons thinks, it's the absence of "basicality" —and not "evidential" conscious sensory or perceptual states - that really matters (2009, p. 112).

To creep up on this idea, Lyons first distinguishes two reliability theories: simple (SR) and inferential (IR):

(SR): a belief is prima facie justified iff it is the result of a reliable cognitive process.

(IR): (i) a basic belief is prima facie justified iff it is the result of a reliable cognitive process, and (ii) a nonbasic belief is prima facie justified iff it is the result of a reliable inferential process, the inputs to which are themselves (prima facie) justified.

Lyons grants that Norman undermines SR. "My own view is that the clairvoyance objection is a sound objection to SR" (2009 p. 114). But he doesn't think it is a counterexample to IR. For unlike SR, he claims, "IR does not imply that Norman...is justified" (2009 p. 115). Why not?

Because IR allows for the possibility of reliably formed non-basic beliefs that are nevertheless not inferentially supported from reliably formed basic beliefs. IR allows that some beliefs, even though reliably formed, still lack warrant; reliability is not always sufficient for warrant.

On IR, if Norman's beliefs are non-basic and not inferentially supported from reliably formed basic beliefs, they lack warrant. Reliability would not matter. But since IR doesn't say which beliefs are basic and which are not-it simply helps itself to the distinction-it is silent on whether Norman's beliefs are warranted.

So it may turn out that Norman's case is a counterexample, once a theory of what makes a belief basic enters the arena. So what Lyons needs to really diffuse the case is a theory of basicality that entails Norman's beliefs are not basic.

I bet Lyons was led to this after discovering the following simple recipe for constructing clairvoyance type counterexamples. Take any belief that, for humans at least, is plausibly inferentially warranted by other evidence if warranted at all. "If you want to know whether four-dimensionalism is true, what blood type someone is, the age of the earth, or the proper cladistic tree for primate phylogeny, you will have to engage in some inference....For a cognizer like us, there are simply some [beliefs] that can't be justified without evidential support from other beliefs. These are the non-basic beliefs for us" (pp. 122-123). Then stipulate that an individual, by some random fluke or mutation, comes to reliably form such beliefs without 
inferential, evidential support. Voilà, the intuition that those reliably formed beliefs nevertheless lack warrant pops out. (2009, pp. 122, 135).

4. So to block such cases and diffuse anti-reliabilist intuitions, Lyons first presents a psychological account of basic beliefs. A belief is basic, he holds, if it is the output of a primal system. A belief is the output of a primal system iff:

(a) it's inferentially opaque (i.e. its doxastic outputs are cognitively spontaneous; they are not the result of an introspectible train of reasoning from earlier beliefs. The only introspectively accessible inter-level representations produced by the system are nondoxastic) (2009, pp. 95, 136).

(b) the system has developed as the result of the interplay of learning and innate constraints.

Lyons arrived at this view through a detailed chapter length discussion of modules, systems, perceptual systems and perceptual beliefs (chap. 4). He settles on (a) and (b) after abstracting away features peculiar to ordinary perceptual systems. For he wants a theory of basic belief more general than simply perceptual belief. His choice of the term 'primal' is "intended to reflect the etiology of the system...a system that just came into being overnight would fail to satisfy the etiological constraint" (2009, pp. 136-137). Origins matter to basicality. Origins thus matter to warrant.

Now because of the possibility that even primal systems may take beliefs as inputs, Lyons adds a condition and then settles on the following definition:

A belief B is basic for $S$ at $t$ iff $B$ is the output of one of S's cognitive systems that (i) is inferentially opaque, (ii) has resulted from learning and innate constraints, and (iii) does not base B on any doxastic inputs at $t(2009$, p. 144).

With this definition in hand, he diffuses the clairvoyance cases. Norman's clairvoyance belief isn't basic, on this definition, for it's "not the result of a system that satisfies the etiological constraint....Though the relevant systems are noninferential, they are not primal, and this is why their outputs are nonbasic" (2009, p. 144). And so on IR, even though Norman's clairvoyance non-inferentially and reliably forms true beliefs, those beliefs are not warranted. Norman's clairvoyance has the wrong origin. Even if non-inferential (and so psychologically basic on most accounts), the process is not innate (or learned). If not innate (or learned), the beliefs are not basic. If not basic, not warranted by sheer reliability. Counterexample diffused.

To buttress his case, he offers a related case with the right origins. Consider Nyrmoon:

Nyrmoon is a member of an alien species for whom clairvoyance is a normal cognitive capacity, which develops in much the same way as vision does for humans. Members of Nyrmoon's species have specialized internal organs that are receptive to the highly attenuated energy signals from distant events... [as he matured] he learned to attend selectively, recognize various objects, and filter out coherent distal events. Nyrmoon, however, is so extremely unreflective that he has no beliefs (a fortiori, no justified beliefs) about the reliability of his clairvoyance. One day he forms, as the result of clairvoyance, the belief that his house is on fire (which it is) (2009, p. 119; Goldman 1988). 
Norman and Nyrmoon differ in at least two ways. First, Norman is one a billion, the first to acquire clairvoyance, in some lucky, accidental way. It just "popped into existence" (2009, p. 144). Nyrmoon, on the other hand, is a member of a species where clairvoyance is standard equipment. Second, Nyrmoon has trained up, in the ordinary way, his use and reliance on clairvoyance. Nyrmoon's system has the same "developmental trajectory as our perceptual systems" (2009, p. 144). Norman's clairvoyance does not. So Norman's clairvoyance is neither innate, nor appropriately "learned." But Nyrmoon's is both. Norman's clairvoyance has the wrong origin; Nyrmoon's has the right one.

What's your reaction? Norman out, Nyrmoon in? Lyons's view is clear. "I have no intuitive problem at all with the claim that Nyrmoon's belief is justified. In fact, my own intuition is positively in favor of his being justified" (2009, p. 119).

I agree with Lyons on this score. Norman's out; Nyrmoon's in.

5. But I think Lyons implicitly appeals to additional facts to reach this result. For consider the following variation on Norman. Instead of achieving his clairvoyance through some random mutation as a full-grown adult, imagine instead the mutation written into his genes. Maybe one of his parents stepped in radioactive waste just before conception. Norman then has the mutation at birth. Suppose again he's one in a billion. Suppose he doesn't learn about its reliability. He just forms beliefs as a result. The process is innate-it's written into his genes. But warrant conferring? How is the original Norman really any different from this Norman? Shouldn't modified Norman prove just as much a problem for Lyons' view as original Norman does for Standard Reliabilism? Why should mere innateness matter? What has innateness got to do with warrant?

When Lyons enumerates the two differences between the original Norman and Nyrmoon, he mentions not just that Norman is one a billion, but also that Nyrmoon is typical for his species; they all have clairvoyance; they all use it; and they all go through normal stages of development. Nyrmoon's clairvoyance is like our ordinary perceptual competence. But here's a well-known, often philosophically underappreciated fact: our perceptual competence evolved over generations to, in part, reliably represent distal objects and features of our environment, and to reliably induce true beliefs, true beliefs that in turn guide our behavior in our surrounds. In the animal kingdom, perception is a paradigm case of an adaptation. But then what's true of us is surely true of Nyrmoon's species as well. Just as we have perception innately because of natural selection, so too Nyrmoon has clairvoyance innately because of natural selection. It's the best explanation for complex adaptive traits. Clairvoyance, for Nyrmoon, evolved by natural selection to reliably represent the environment, and reliably induce true beliefs that led, often enough, to adaptive behavior. Original and modified Norman differ from Nyrmoon, for Nyrmoon's clairvoyance-like ordinary human perception-resulted from selection for reliability, but original and modified Norman got their clairvoyance merely by mutation. It's not an adaptation; it's just a mutation. So it is not innateness per se that matters, but why the system is innate that matters. Lyons is right that etiology matters to warrant. He just didn't spell out the entire etiology that matters.

6. Not only did Lyons leave the etiology underspecified, he also failed to provide an argument or general account showing why warrant should turn on a combination 
of innateness (or learning) and reliability. He only relied on cases. But I think a general account can be provided. Here is how such an account might go (for elaboration and defense, see Graham (forthcoming)).

First, embrace the etiological account of functions, derived from Larry Wright and developed by Ruth Millikan, Peter Godfrey-Smith, Karen Neander, among others. The heart is for pumping blood; that is its function. On the etiological account, that's because ancestors of our hearts pumped blood, and by pumping blood contributed to fitness, and did so better than alternatives. Less effective hearts were selected out. By doing so our ancestors led to their own replication, and to the existence of current hearts. Applied to biological kinds, the etiological function of an item is the effect of ancestors of the kind that helps explain why the kind contributed to fitness under selection, and thereby helps explain why descendants were produced on the model of ancestors. Roughly, an etiological function of a biological kind is the effect it was naturally selected for.

The etiological account of functions isn't limited to biological kinds. It applies to any kind of item-social practices, words, forms of behavior, even artifacts—copied and selected in any way for one or more of its effects. Perceptual learning is a selective process too.

Second, note that for any item with an etiological function there is a historical explanation for how the item came to have that function: by having a certain effect while operating in a certain way in circumstances of a certain kind. A muscle in an organism's chest pumps by beating regularly. In turn it is connected in a systematic way with other parts of the organism, embedded in a certain kind of habitat. If pumping blood explains, in part, why the muscle gets reproduced, then it comes to have pumping blood as an etiological function. For any item with an etiological function, there is a historical explanation that explains how the item, by working a certain way in certain conditions, contributed to its own replication and persistence (Millikan 1984, pp. 33-34). Millikan calls these explanations 'Normal explanations.'

Third, pull out from the Normal explanation an account of normal functioning and normal conditions. Normal functioning is the way the item functioned (operated, worked) when it (or the system of which it is a part) was selected for. Normal conditions are those circumstances (and relevantly similar ones) where all of this happened.

Fourth, notice that the Normal explanation entails that for any item with an etiological function, ceteris paribus normal conditions plus normal functioning leads, often enough, to function fulfillment. For if normal functioning in normal conditions didn't lead to function fulfillment, then the item would have not been selected for the effect that is its function. Given that's its function, it must have produced the effect in normal conditions when functioning normally. Hence, ceteris paribus, it fulfills its function in normal conditions when functioning normally.

Fifth, notice then that on the etiological account of functions, normal functioning and normal conditions, we can partially individuate normal functioning or normal conditions in terms of the item's function. In particular, normal functioning for an item with an etiological function just is functioning (operating) in a way that ceteris paribus in normal conditions leads to function fulfillment. If it didn't contribute to function fulfillment when operating that way, then that way would not be normal 
functioning. Normal functioning is thus constitutively associated with function fulfillment. $^{2}$

Given that our perceptual belief-forming systems have inducing true beliefs reliably as an etiological function - they were selected, in part, for reliably inducing true beliefs; that's how they help us find food, mates, and so on-it follows that normal functioning for our perceptual systems is constitutively associated with reliably inducing true beliefs.

Sixth, note that for any item with an etiological function, there are two norms (or standards) constitutively associated with the item's function. First, there is function fulfillment. That's obvious. Functions are norms or standards. Fulfilling its function is something an item with a function is supposed to do. Second, there is normal functioning. A heart that functions (operates, works) normally functions (operates, works) as it should, the way it is supposed to function (operate, work). When it beats regularly, it is functioning normally, functioning correctly. A heart that is not functioning normally is a malformed or dysfunctional heart; it is not working (functioning) normally, the way it should.

Seventh, identify various goods, successes, or achievements with meeting norms or standards. Function fulfillment is thus a good or success for the item with the function. Normal functioning is too.

Eighth, identify warrant with a good or success understood in terms of promoting truth and avoiding error that attaches primarily to beliefs. Identify entitlements with warrants (or contributions to warrant) that are not reasons (warranted propositional attitudes) held by the individual.

Now put two and two together. Human perception has the etiological function of reliably inducing true beliefs. Normal functioning for human perception is thus constitutively associated with reliably promoting true beliefs and avoiding errors. Normal functioning for human perception is thus a good or success understood in terms of promoting truth and avoiding error. Voilà, human perceptual entitlement consists in the normal functioning of the perceptual system and the transition to perceptual belief.

It's transparent on this general account why innateness matters to warrant. For the etiology of the system involves selection for reliably getting things right. It thereby sets epistemic norms or standards. Warrant consists in meeting such norms.

And since (on the etiological account of functions) first generation mutations have no functions, nothing counts as normal functioning for original and modified Norman's clairvoyant systems. And since you and I and Nyrmoon have the right evolutionary histories, our perceptual and his clairvoyant induced beliefs all enjoy warrant.

\footnotetext{
2 This contrasts with conscious, intentional, assigned functions and design plans. On the etiological account, functions, normal functioning, and normal conditions are all holistically interrelated. Not so for intentionally assigned functions. One can assign a function that the device never fulfills. Think of the dustbin of failed inventions. One can design a plan for how the device should work that never produces intended effect. One can even have circumstances in mind where the device is bound to fail. For assigned functions, these notions are atomistically distinct. This fact marks an important difference with other teleological accounts like Plantinga's (1993) and Bergmann's (2006). Normal functioning, on their views, isn't constitutively associated with function fulfillment. So it's not obvious why normal functioning is an epistemic achievement on their views. I explore this difference for explaining warrant elsewhere.
} 
And if all that weren't good enough to sell Lyons on the idea, this account of perceptual entitlement also nicely treats the case of the massively deceived, disembodied brain-in-a-vat.

Consider two cases. A surgeon might remove a subject's heart and place it in a sterile container where it still receives electrical signals and so continues to beat normally, even though no blood is passing through. It is still a healthy heart-it functions normally-even though it is not fulfilling its function. Or imagine your car up the lift for an inspection. The engine, crank shaft, wheels and tires may all operate the way they are supposed to - the whole car is functioning normally-even though you are not traveling to your destination.

Likewise a brain may be placed in a vat of nutrients and hooked up to a supercomputer. It may still function (operate) just fine, even if massively deceived about its physical surrounds. It may meet norms constitutively associated with promoting truth and avoiding error, even though every perceptual belief formed in its present circumstances is false. Perceptual entitlement entails, ceteris paribus, that a normally functioning perceptual system will induce mostly true beliefs in normal conditions, but perceptual entitlement (on the account just sketched) does not require that the subject be in normal conditions, for a system may function normally outside of normal conditions. Reliability may lapse while entitlement persists.

Since the brain-in-vat forms "basic" perceptual beliefs on Lyons' account of basicality, but doesn't form reliably true beliefs while in the vat, its beliefs are not “justified" on Lyons's view. He may get Nyrmoon and (original) Norman right, but neither modified Norman nor the brain-in-a-vat. But the account I've just sketched gets all four just right. And so the account provides a general explanation of why etiology and reliability matter for warrant, and seems to get the cases just right. Though I'm sure Lyons will find a few outstanding problems with the account, I recommend it to him. It's just what he's looking for. ${ }^{3}$

7. Evidentialists won't believe a word of this. Sure, the brain-in-a-vat may function just fine. But it's his evidence that really matters. And Norman's clairvoyance may have no function, but it's the lack of evidence that really matters. A debate between two reliabilists isn't likely to grab their attention, let alone change their minds. I wish I had time to discuss everything Lyons has to say against evidentialism in our mutual defense. Instead I'll simply pass the baton back to Lyons, and thank him for his excellent, richly argued and rewarding book.

Open Access This article is distributed under the terms of the Creative Commons Attribution Noncommercial License which permits any noncommercial use, distribution, and reproduction in any medium, provided the original author(s) and source are credited.

\section{References}

Bergmann, M. (2006). Justification without Awareness. New York: Oxford University Press. BonJour, L. (1980). Externalist Theories of Empirical Knowledge. Midwest Studies in Philosophy, 5, $53-73$.

\footnotetext{
3 I expect he'll doubt that it can adequately cover Lehrer's Truetemp and Davidson's Swampman. Space doesn't allow me to discuss those cases here. See Graham (forthcoming) for replies.
} 
Burge, T. (2003). Perceptual Entitlement. Philosophy and Phenomenological Research, 67(3), 503-548. Goldman, A. (1979). In G. Pappas (Ed.), “What is Justified Belief?”. Reidel: Justification and Knowledge.

Goldman, A. (1988). Strong and Weak Justification. Philosophical Perspectives, 2, 51-70.

Graham, P. J. (forthcoming). Epistemic Entitlement. Nô̂s.

Lehrer, K. (1990). Theory of Knowledge. Boulder: Westview Press.

Lehrer, K., \& Cohen, S. (1983). Justification, Truth, and Coherence. Synthese, 55, 191-207.

Lyons, J. C. (2009). Perception and Basic Beliefs: Zombies, Modules, and the Problem of the External World. New York: Oxford University Press.

Millikan, R. (1984). Language, Thought, and Other Biological Categories. Cambridge: The MIT Press. Plantinga, A. (2000). Warrant and Proper Function. New York: Oxford University Press. 